\title{
Web evaluation of maceration length period on antioxidant potency of Sonneratia caseolaris leaf
}

\author{
Feni Iranawati ${ }^{1,2 *}$, Rizqi Narulitai ${ }^{1}$, Citra Satrya Utami Dewi ${ }^{1}$, Sunanto Arifin ${ }^{3.4}$ \\ ${ }^{1}$ Marine Science Department, Fisheries and Marine Science Faculty of Brawijaya University, 65145, \\ Indonesia \\ ${ }^{2}$ Marine Resources Exploration and Management (MEXMA) Research Group, Brawijaya University, \\ 65245, Indonesia \\ ${ }^{3}$ Pharmacy Academy, Putra Indonesia Foundation, 65126, Indonesia \\ ${ }^{4}$ Sekolah Tinggi Ilmu Perikanan (Fisheries Science College), 65141, Indonesia
}

\begin{abstract}
Diabetic and cancer, as an examples of degenerative diseases in human may arise as consequences of free radicals, i.e. highly reactive molecules. The reactiveness of free radicals can be constrained by a substance, known as antioxidant. Mangroves that inhabitant of highly dynamic waters of estuary is likely have defend activity by produce some substances those known as bioactive compounds that may have potency of antioxidant. The quality and quantity of bioactive compounds may affected by extraction method. This study aims to evaluate antioxidant potency of Sonneratia caseolaris leaf with three diferent length time $(24,48$ and 72 hours) of maceration by applying of DPPD (1,1-diphenyl- $\beta$-picryl hydrazyl) method. Result based on $50 \%$ of inhibition concentration $\left(\mathrm{IC}_{50}\right)$ value suggest that the best maceration time is 24 hours ( $\mathrm{IC}_{50}$ was $6.35 \mathrm{ppm}$ ), following by 72 and 48 hours ( $\mathrm{IC}_{50}$ were 11.5 and $17.4 \mathrm{ppm}$, respectively). In addition, overall of different maceration time show IC value lowe than 50 ppm, indicate that Sonneatia caseolaris leaf have very strong potential of antioxidant activity.
\end{abstract}

\section{Introduction}

Degenerative diseases, such as cancer, stroke, rheumatism, heart disease, kidney failure and hypertension were triggered by several causes, one of them is free radicals. In living organisms, free radicals are produces as metabolism residual of protein, carbohydrates and fat. Antioxidants are compounds used to reduce free radicals that can be originated naturally from plant fluids or from factory production [4]. One of the compounds contained in plants is bioactive compounds. Bioactive compounds are one of the secondary metabolites produced by plants through a series of secondary metabolic reactions. This secondary metabolite compound in plants is usually used as a defense and protection mechanism to fight predators [3]. In addition, the higher the environmental pressure given to plants, the more secondary metabolites are produced [13]. Bioactive compounds in plants also have advantages for other living organism, especially for humans. These compounds have various benefits, including as source of antioxidants, antibacterial, anti-inflammatory and can also be used as a

\footnotetext{
* Corresponding author: fe_iranawati@ub.ac.id
} 
prevention of cancer [1]. The content of bioactive compounds can also function as immunomodulators, metabolic blocking prevention for dyslipidemia, diabetes and obesity $[2]$.

Plants that have the potential as medicinal plants contain bioactive compounds such as alkaloids, terpenoids, phenolics, steroids, and flavonoids with varying amounts. Mangroves are believed to contain bioactive compounds that have the potential as natural antioxidants. Mangrove $S$. caseolaris has a potential as a natural antioxidant due to several bioactive compounds such as terpenoids, flavonoids, tannins and phenol hydroquinos had been identified from this plant [10]. Parts of fruit, bark, and leaves of this mangrove species have been reported being used to make of traditional medicine [12]. Withdrawing an active substance in plant can be accomplished with extraction process using solvents. In this study the extraction process was performed by maceration.

The length of maceration time as part of extraction process may affect the quantity and quality of the bioactive compounds that can be extracted from a substance, thus influencing their bioactivity such as antioxidants. Shorter maceration time will lead to insoluble bioactive compounds, whereas longer maceration time which will lead to damage the bioactive compounds of the sample [14]. Therefore, to find the optimal antioxidant activity of $S$. caseolaris leaf, the length of maceration time should be evaluated. The study objective is to evaluate different length of maceration of extraction (24, 48 and 72 hours) towards antioxidant activities of $S$. caseolaris using 1,1-diphenyl- $\beta$-picryl hydrazyl) (DPPH) method.

\section{Materials and methods}

Research was conducted from January to April 2018. Sample of S. caseolaris leaf was collected from the coastal area of Serang, Blitar Regency, East Java and laboratory analysis was conducted at the Fisheries and Marine Resources Exploration Laboratory of the Faculty of Fisheries and Marine Sciences, Universitas Brawijaya. The research was experimental research performed with two-way ANOVA design, with first factor is the maceration length time consisting of A ( 24 hours), B ( 48 hours) and C ( 72 hours) whereas the second factor is the extract concentration consisting of $5 \mathrm{ppm}, 10 \mathrm{ppm}, 20 \mathrm{ppm}$ and $40 \mathrm{ppm}$. All treatments were repeated 3 times.

\subsection{Samples preparation}

Samples of mangrove leaves of $S$. caseolaris taken were leaf that were dark green and the shape is still intact, then weighed overall. The collected $S$. caseolaris mangrove leaf samples were washed using clean running water to remove the impurities in the leaf samples. Leaf samples that have been washed and then wiped with tissue. Drying the sample at the next stage is carried out for 16 days in the green house to reduce the water content in the sample.

\subsection{Samples extraction}

Sample extraction method used maceration by soaking 200 grams of dried leaf sample in 600 $\mathrm{ml}$ of methanol solvent for 24 hours (treatment A), 48 hours (treatment B) and 72 hours (treatment $\mathrm{C}$ ). When the maceration process is complete, the solvent was filtrated using Whatman no. 42 , then the filtrate was evaporated at $44^{\circ} \mathrm{C}$ for 60 minute and the extract resulted will be used for antioxidant testing. 


\subsection{Antioxidant testing}

The antioxidant activity of $S$. caseolaris leaf extract was carried out with DPPH $(1,1-$ diphenyl-2-picrylhydrazyl) method follows [6], with the concentration of each treatment which is $5 \mathrm{ppm}, 10 \mathrm{ppm}, 20 \mathrm{ppm}$ and $40 \mathrm{ppm}$. The antioxidant activity was evaluated base on qualitative result (sample color changes) and quantitative result (50\% inhibition concentration or $\mathrm{IC}_{50}$ ) applying absorbance value at $571 \mathrm{~nm}$. Absorbance of blank solution in the antioxidant test was carried out by mixing $0.5 \mathrm{mM}$ DPPH (1,1-diphenyl-2pikrilhidrazil) solution and methanol with a ratio of $1: 3$. This solution is then homogenized and incubated for 30 minutes at dark room temperature and then the absorbance is measured by a UV-Vis spectrophotometer with a wave length of $517 \mathrm{~nm}$. Positive control on the antioxidant test used ascorbic acid with concentrations of 2, 4, 6 and $8 \mathrm{ppm}$.

\section{Result and discussion}

Qualitative test of antioxidant shows that color change of sample from purple to yellow was occurred at sample concentration of $20 \mathrm{ppm}$ and $40 \mathrm{ppm}$, while at sample concentration of 5 $\mathrm{ppm}$ and $10 \mathrm{ppm}$ the color changed was purple to light purple. This indicates that higher sample concentration has higher antioxidant activity that can be seen when the sample color change from purple to yellow (Figure 1). This is supported by [8] that the presence of antioxidant activity in the samples tested was marked by a change in purple to yellow. This is because the antioxidant compounds from Sonneratia caseolaris mangrove leaf extract donate protons to DPPH free radicals (1,1-diphenyl-2-picrylhydrazyl). According to [9], antioxidant compounds will react with DPPH radicals through the mechanism of donating hydrogen atoms and causing changes in color from purple to yellow. The purple, DPPH color intensity will decrease according to the concentration and ability of the compound to inhibit free radicals. From the qualitative test it can be inferred that the higher the concentration of the sample used during testing, the greater the color change that occurs from purple to yellow. The greater concentration of samples used, the higher the antioxidant content that will have an impact on the level of inhibition of free radicals carried out by antioxidants. This is in accordance with [5] suggestion that the higher the concentration used, the higher the percentage inhibition value.

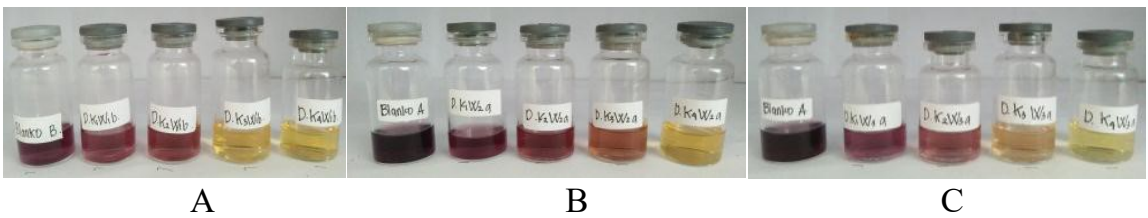

Fig. 1. Result of DPPH test of of S.caseolaris leaf extract for different maceration time; (A) 25 hours; (B) 48 hours and (C) 72 hours; from left to right were different concentrations of $0,5,10,20$ and $40 \mathrm{ppm}$, respectivley

Quantitative antioxidant test results were obtained from measurements of absorbance values using a UV/VIS spectrophotometer at a wavelength of $517 \mathrm{~nm}$. From the absorbance value can be calculated the percentage of inhibition value with the formula:

$$
\frac{\text { (Blank absorbance - sample absorbance) }}{\text { Blank absorbance }} \times 100 \%
$$


$\mathrm{IC}_{50}$ values show the amount of sample concentration that can inhibit $50 \%$ of free radicals. $\mathrm{IC}_{50}$ values were obtained by applying linear regression equations which illustrate the relationship between the sample concentrations (x axis) and percent of inhibition (y axis) and the $\mathrm{IC}_{50}$ value for each treatment can be seen in Figure 2.

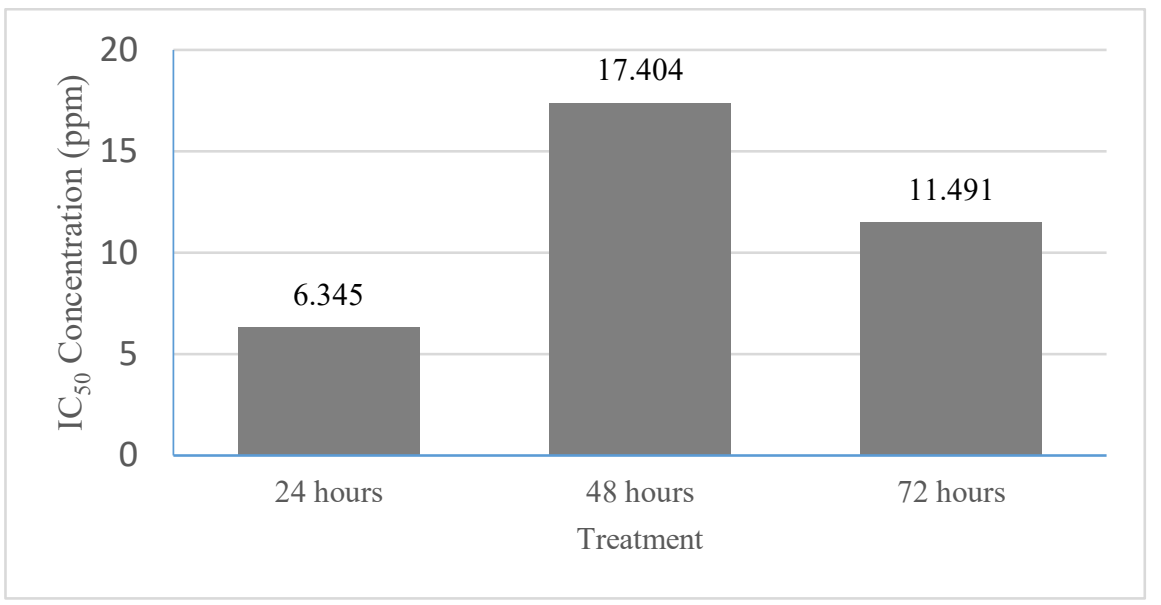

Fig. 2. $\mathrm{IC}_{50}$ value of $S$. caseolaris leaf

Figure 2 shows that $\mathrm{IC}_{50}$ values of all the maceration treatment that have been observed were lower than $50 \mathrm{ppm}$. This indicates that all methods resulted in very strong antioxidant activity. The two-way ANOVA results showed that the treatment of 24-hour maceration of S. caseolaris extract leaf had higher antioxidant activity compared to the treatment of 48 hours and 72 hours maceration (Sig. $0,000<0,05$ ). The lowest $\mathrm{IC}_{50}$ values was obtained from maceration 24 hour, indicates that this length of maceration time is the best method that yielded highest antioxidant activity. According to [11], the lower the $\mathrm{IC}_{50}$ value, the higher the ability to inhibit free radicals. Generally, extract of a compound is considered to be; a very strong antioxidant if the $\mathrm{IC}_{50}$ value $<50 \mathrm{ppm}$, strong antioxidant for $\mathrm{IC}_{50}$ is ranged at 50 $100 \mathrm{ppm}$, moderate antioxidant if it is ranged $100-150 \mathrm{ppm}$, and weak antioxidant if the $\mathrm{IC}_{50}$ value is higher than $151 \mathrm{ppm}$.

Based on the statistical analysis results it can be seen that the extract concentration has an effect on the antioxidant activity (Sig. $0,000<0,05$ ) while the interaction between the length of maceration and the concentration of S. caseolaris leaf extract shows no interaction between them (Sig. 0,05). The further results of the antioxidant activity showed that there was no significant difference of antioxidant activity at extract concentration of $5 \mathrm{ppm}$ with a concentration of $10 \mathrm{ppm}$, but it had a significant difference with concentrations of $20 \mathrm{ppm}$ and $40 \mathrm{ppm}$. Based on the mean difference value between concentrations, the concentration of leaf extract $S$. casolaris which showed the highest antioxidant activity was a concentration of $40 \mathrm{ppm}$.

\section{Conclusion}

Based on the value of $\mathrm{IC}_{50}$ and the length of time use for maceration, the 24 hours of maceration was the best extraction method that has the highest antioxidant activities whereas the best extract of $S$. caseolaris leaf with the highest antioxidant activities is a concentration of $40 \mathrm{ppm}$. 
The author would like to give gratitude for the support provided by the Faculty of Fisheries and Marine Science of Universitas Brawijaya and Marine Resources Exploration and Management (MEXMA) Research Group.

\section{References}

1. A. Altemimi, N. Lakhssassi, A. Baharlouei, D. Watson, D. Lightfoot, Plants 6, 42 (2017)

2. R. Arreola, S. Quintero-Fabián, R. López-Roa, E. Flores-Gutiérrez, J. Reyes-Grajeda, L. Carrera-Quintanar, D. Ortuño-Sahagún, of immunol. research, 401630 (2015)

3. S. Asad, M. Hamiduzzaman, A. Azam, M. Ahsan, M. Mehedi, International Journal of Advanced Research in Pharmaceutical \& Bio Sciences 3(4), 1-10

4. M. Brewer, Comprehensive Reviews in Food Science and Food Safety 10 (4), 221-247 (2011)

5. H. Gubler, U. Schopfer, E. Jacoby, J. of Biomolecular Screening 18(1),1-13 (2012)

6. F. Iranawati, F. Muhammad, H. Fajri, R. Kasitowati, S. Arifin, IOP Conference Series: Earth and Environmental Science 137(1), 012063

7. S. Jayarathne, I. Koboziev, O. Park, W. Oldewage-Theron, C. Shen, N. MoustaidMoussa, Preventive nutrition and food science 22 (4), 251-262 (2017)

8. P. Molyneux, Songklanakarin Journal Science Technology 6(2), 211-219 (2004)

9. S. Kedare, R. Singh, Journal of food science and technology 48(4), 412-422 (2011)

10. S. Sadhu, F. Ahmed, T. Ohtsuki, M. Ishibashi, Journal of Natural Medicine 60(3), 264 265 (2006)

11. P. Sibuea, Antioksidan senyawa ajaib penangkal penuaan dini (Sinar Harapan, Yogyakarta, 2003)

12. A. Simlai, A. Roy, Pharmacognosy reviews 7(14), 170-178 (2013)

13. L.Yang, K-S. Wen, X. Ruan, , Y-X. Zhao, F. Wei., Q. Wang, Molecules 23(4), 762 (2018)

14. Q. Zhang, L. Lin, W. Ye, Chinese medicine 13, 20 (2018) 